\title{
Science and Values in Undergraduate Education
}

\section{Edwin Koster ${ }^{1} \cdot$ Henk W. de Regt ${ }^{2}$ (C)}

Published online: 10 December 2019

(C) The Author(s) 2019

\begin{abstract}
While a conception of science as value free has been dominant since Max Weber defended it in the nineteenth century, recent years have witnessed an emerging consensus that science is not - and cannot be - completely free of values. Which values may legitimately influence science, and in which ways, is currently a topic of heated debate in philosophy of science. These discussions have immediate relevance for science teaching: if the value-free ideal of science is misguided, science students should abandon it too and learn to reflect on the relation between science and values - only then can they become responsible academics and citizens. Since science students will plausibly become scientists, scientific practitioners, or academic professionals, and their values will influence their future professional activities, it is essential that they are aware of these values and are able to critically reflect upon their role. In this paper, we investigate ways in which reflection on science and values can be incorporated in undergraduate science education. In particular, we discuss how recent philosophical insights about science and values can be used in courses for students in the life sciences, and we present a specific learning model - the so-called the Dilemma-Oriented Learning Model (DOLM) - that allows students to articulate their own values and to reflect upon them.
\end{abstract}

Keywords Undergraduate education · Value-freedom of science - Epistemic and non-epistemic values $\cdot$ Dilemma-oriented learning model $\cdot$ Objectivity $\cdot$ Dialogue

Henk W. de Regt

henk.deregt@ru.nl

Edwin Koster

e.koster@vu.nl

1 Department of Philosophy, Faculty of Humanities, Vrije Universiteit Amsterdam, De Boelelaan 1105, 1081 HV Amsterdam, Netherlands

2 Institute for Science in Society, Faculty of Science, Radboud University, P.O. Box 9010, 6500

GL Nijmegen, Netherlands 


\section{Introduction}

Science is about the facts and nothing but the facts. This view is quite common among scientists and laypeople alike and accordingly also among (aspiring) science students (Corrigan et al. 2007: 1-2; Fisher and Moody 2002; Kincaid et al. 2007: 13-14; King and Kitchener 2004). It entails that (good) science is "value free": scientific research and its results should not be contaminated with values of any sort, whether political, religious, moral, social, or economic values. The conception of science as a value-free enterprise has been widely accepted and very influential at least since Max Weber defended it in the nineteenth century. In recent decades, however, a growing number of philosophers of science has cast doubt on it, and a consensus is emerging that science is not - and cannot be - completely free of values. Which values may legitimately influence science, and in which ways, is currently a topic of heated debate in philosophy of science. These discussions have immediate relevance for science teaching: if the value-free ideal of science is misguided, science students should abandon it and learn to reflect on the relation between science and values - only then can they become responsible academics and citizens.

In this article, we investigate ways in which reflection on science and values can be incorporated in undergraduate science education. While we think this holds across a wide variety of scientific disciplines, we focus on the life sciences. In particular, we discuss how recent philosophical insights about science and values can be used in courses for science students, and we present a specific learning model that allows students to articulate their own values and to reflect upon them. ${ }^{1}$ We hope and expect that university lecturers can benefit from this article and can apply our model in their own teaching (cf. Koster and Boschhuizen 2018).

The outline of the article is as follows. Section 2 reviews the current debate about science and values in philosophy of science. The notion of value-free science is analyzed in detail, and different types of values that may affect science are identified. An especially relevant distinction is that between epistemic and non-epistemic values, the most challenging discussions are about the (legitimate or illegitimate) roles of non-epistemic values at the heart of scientific practice. In Section 3, we substantiate our claim that these philosophical discussions are highly relevant for undergraduate science education: students need to critically think about the relation between science and values. The question of how this can be achieved is discussed with reference to a Bachelor course that one of us (EK) teaches to students in the Biomedical Sciences. In this course, students (who have no rich background in philosophy of science and have little experience in actual scientific research) are stimulated to develop a critical approach to science via systematic presentation of examples of the interaction between scientific research, on the one hand, and epistemic and non-epistemic values, on the other. Section 4 explicates the "Dilemma-Oriented Learning Model" (DOLM), used in the abovementioned course. This model helps students to reflect upon their "own" values: values that are typically related to their background and personal convictions. Because these students will plausibly become scientists, scientific practitioners, or academic professionals and because their values will influence their future professional activities, it is essential that they are aware of these values and are able to critically reflect upon their role. Section 5 concludes the article by discussing some wider implications.

\footnotetext{
${ }^{1}$ Allchin (1999) contains a comparable plea for paying attention to the interaction between science and values in science teaching. Our paper presents a more developed proposal for doing so, based upon recent insights from philosophy of science and science education.
} 


\section{Science and Values: Lessons from Philosophy}

The value-free ideal has dominated our conception of science for a very long time (Carrier 2008: 1-7; Kincaid et al. 2007: 5-6; Stenmark 2006: 49-53). In its strongest version, it expresses the view that the sole aim of science is to disclose facts about the world, and that facts can and should be sharply distinguished from values. Building on an empiricist tradition going back to Locke and Hume, logical positivist philosophers of science argued that science should be based on logic and sensory experience alone, so that it would yield objective factual knowledge of the world - independently of the subjective perspectives or opinions of individual scientists. Science can only tell us how the world is, not how it should be - and, conversely, scientific research is not affected by our ideas about how the world should be, by our value judgments. For logical positivists, scientific knowledge should be verifiable through observation or experiment, and the truth of value judgments like "torturing animals is wrong" can never be verified in this way (they regarded value judgments as expressions of emotions). Hence, they excluded value judgments from the domain of science.

At this point, we need to say a bit more about the nature of values. Above, we mentioned political, religious, moral, social, and economic values, and one might add, for example, aesthetic and personal values. So there appear to be many kinds of values, but is there a general definition or characterization of the notion of value? There is no easy answer to this question. McMullin (2000: 550) suggests the following: "to value something is to ascribe worth to it, [...] to regard it as desirable," and a value is "the characteristic that leads something to be so regarded." 2 Reasons for valuing something can range from purely subjective preferences of the person who values it to features that are objectively required for that something to function properly. For example, when someone buys a specific raincoat because it is waterproof and attractively designed, both properties are valued (by that person), but the former valuation is less subjective than the latter. Notwithstanding such variation, the standard conception of values (endorsed by the logical positivists) entails that values always involve some subjectivity, because something can only be a value when it can be valued by a human agent. (This also applies to the raincoat, whose being waterproof is a value only because people are interested in using the raincoat to protect themselves from the rain.) There can be many different sources of values: ideologies (e.g., political, economic), religious or metaphysical beliefs, interests (e.g., personal, financial), and so on. For example, a gambler who has a financial interest in Zenith winning tomorrow's horse race will value Zenith's healthy condition. Of course, a healthy condition is generally valued in any race horse, but note that this gambler would value an inferior physical condition in Zenith's competitors. While particular interests, or commitments to a particular ideology or religion, can thus inspire or even compel one to adopt certain values, such commitments and interests are not in themselves values.

Back to science. The strong value-free ideal sketched above has been challenged in many ways and is generally rejected nowadays. A fundamental - albeit controversial - criticism focuses on the fact-value distinction itself, arguing that in many cases this distinction cannot be drawn (see, e.g., Dupré 2007). A less radical, and more generally accepted, critique proceeds from the observation that there are some values that are obviously central to, if not constitutive of, science - where the prime example is truth. So, the question does not seem to be whether

\footnotetext{
${ }^{2}$ A similar analysis is given by Lacey (1999: 27): "When an agent (X) holds a value (v), the fundamental expression is ' $\mathrm{X}$ values that $\varnothing$ be characterized by v'," where the nature of $\varnothing$ determines the kind of value (e.g., if $\varnothing$ is a work of art, $\mathrm{v}$ is an aesthetic value; if $\varnothing$ is a society, $\mathrm{v}$ is a social value, etc.).
} 
values are involved in science, but rather which values are (legitimately) involved and where and how they are involved. These questions have been hotly debated by philosophers of science since Thomas Kuhn's seminal 1977 paper "Objectivity, Value Judgment, and Theory Choice" and a great variety of arguments and perspectives can be found in the literature. ${ }^{3}$ While there is consensus that science is not - and cannot be - value free in the strong sense sketched above, there remain (sometimes deep) disagreements about the legitimate place and role of values in science. As we will see below, some philosophers claim that a weaker version of the value-free ideal can still be maintained, whereas others abandon the ideal altogether.

In order to structure the debate, let us start by raising three different but equally important questions (adapted from Kincaid et al. 2007: 10):

A. Which kinds of values (are allowed to) play a role in science?

B. Where do these values play a role?

C. What effect does their involvement have?

Answers to question (A) often invoke a distinction between epistemic and non-epistemic values. Epistemic values are those values that are conducive to an important aim of science: knowledge production (McMullin 1983: 18). ${ }^{4}$ Kuhn (1977) listed a number of epistemic values that apply to scientific theories: accuracy, consistency, scope, simplicity, and fruitfulness. ${ }^{5}$ Other examples would be explanatory power and unifying power. Epistemic values that apply to scientists may include skepticism, disinterestedness, and openness to counter-evidence. Non-epistemic values, on the other hand, would include, for example, cultural, moral, economic, and political values and also more personal values based on religious commitments, interests, or loyalty to colleagues and sponsors.

While there is debate about which values count as epistemic, no one would contest that epistemic values play a legitimate role in science. ${ }^{6}$ A more important, and more fundamental, question is whether also non-epistemic values are involved in scientific research and, if so, whether their involvement is inevitable or only possible and whether it is always detrimental. Those who want to exclude non-epistemic values from science, maintaining that only epistemic values are allowed to play a role, can be regarded as defending a weak version of the value-free ideal (Kuhn 1977, McMullin 1983, and Dorato 2004 are examples). Their opponents typically argue that non-epistemic values cannot be eliminated from scientific research (either in practice or in principle) but that this does not imply that science is hopelessly subjective: there are ways to retain the objectivity of science other than cleansing it from nonepistemic values (examples are Longino 1990, 2004, and Douglas 2009). Incidentally, some authors reject the (possibility of making a) distinction between epistemic and non-epistemic

\footnotetext{
${ }^{3}$ See, e.g., McMullin 1983, Laudan 1984, Longino 1990, Lacey 1999, Machamer and Wolters 2004, Kincaid et al., 2007, Carrier et al., 2008, and Douglas 2009; see Douglas 2016 and Elliott 2017 for recent overviews.

${ }^{4}$ Of course, this is not the only aim of science, but the philosophical debate on science and values focuses on knowledge production. Other aims of science can, for instance, be related to the material realization of science and to the practice of science.

${ }^{5}$ Kuhn did not use the term "epistemic": he simply called these values "scientific." Others have used different adjectives for the same notion; thus, Longino (1990) speaks of "constitutive" values and Lacey (1999) of "cognitive" values.

${ }^{6}$ After Kuhn (1977), various lists have been presented, e.g., by McMullin (1983), Longino (1990), and Lacey (1999). The most radical proposal is by Longino (1995), who presents a list of alternative feminist epistemic values that complements the more traditional list of Kuhn. Note that reference to epistemic values is usually confined to the problem of theory choice and to the assessment of hypotheses.
} 
values altogether (e.g., Rooney 1992, Douglas 2009). For the purposes of the present paper, we will ignore this debate and assume that the distinction can be made (cf. Pournari 2008).

So far, we have discussed the role of values in science in a quite general way. But science is a complex enterprise, and it is important to carefully differentiate the various stages of scientific practice in which values may or may not be involved. This brings us to question (B): Where do (epistemic or non-epistemic) values play a role? Here it is useful to distinguish between three stages of scientific practice:

I. First stage: choice of research topic and methods

II. Second stage: carrying out the research

III. Third stage: application of research results

In the first stage, before the actual research starts, all kinds of values may play a part. Most importantly, the choice of research topics cannot be made in a value-free manner. ${ }^{7}$ Epistemic values may come into play in this stage, for instance, when competing research proposals are evaluated with help of criteria such as expected explanatory success and breadth of scope. Non-epistemic values are involved as well. When governments, politicians, or business executives decide which types of research will be financed, the values of political parties and private corporations influence the direction of scientific research. And even if scientists (e.g., within a university setting) are free to choose their own topic of research, their personal interests, political ideas, or religious beliefs may affect which issues they want to investigate. The choice of research methods is also value-laden. Epistemic values are clearly relevant here, but in some cases, non-epistemic values can come into play as well: think of financial considerations or ethical restrictions (e.g., research on animals or human subjects). In Section 3.2, we will discuss the role of values in this stage in more detail.

The second stage might be called the "heart" of science: this is where the actual scientific research is carried out. It is this stage in particular that has been the focus of the debate about the value freedom of science since Max Weber and the logical positivists. While their strong value-free ideal has generally been rejected, today's proponents of the weak value-free ideal claim that in this stage, only epistemic values are allowed to play a part. Among such epistemic values are the ones that govern hypothesis or theory construction and selection (see Kuhn's list, cited above). In addition, epistemic values can determine which kind of evidence is to be considered as proof for the hypothesis under scrutiny or govern the way in which evidence is obtained. Whether or not non-epistemic values should also be allowed to play a part in this stage is a matter of debate, however. Advocates of the weak value-free ideal deny this, but other philosophers of science have argued that there is an ineliminable role for non-epistemic values in the second stage as well, because epistemic considerations alone do not suffice to determine theory choice (Longino 2004). ${ }^{8}$ However, allowing non-epistemic values (based, e.g., on ideological commitments, religious beliefs, or interests) to play a role in the construction, acceptance or rejection of scientific claims leaves us with the difficult task of specifying how precisely such value influences are to be managed, for they can easily lead to unwanted bias that

\footnotetext{
${ }^{7}$ One might object that a value-free choice is possible when the topic is chosen at random, e.g., by tossing a coin. But even then, one first has to compile a list of alternatives to choose from, and this will inevitably involve valueladen decisions.

${ }^{8}$ See Intemann 2005 for a critical discussion of this "underdetermination argument."
} 
corrupts the time-honored objectivity of science. Finally, it should be noted that ethical considerations about issues of appropriate conduct in scientific research (e.g., sloppy science, fraud) and, again, about experiments on animals or humans are also relevant in this stage. In Section 3.3, we will discuss the role of values in the second stage in more detail and present some examples.

Finally, in the third stage, results of scientific research are applied in real-world situations. It is quite obvious that this stage involves all kinds of values, also - and perhaps most of all non-epistemic ones. For after a scientific research project is completed, its results can play a role, for example, in political decision-making or in commercial activities of private companies. In such cases, the application of scientific research is always accompanied by, first, implicit or explicit ideas about the good life and a just society and, second, certain economic interests. Science and non-epistemic values can thus be thoroughly intertwined in this stage. In Section 3.2., we provide some examples.

It can be concluded, first, that nobody denies a role for both epistemic and nonepistemic values in the first and third stage, where scientists and policymakers decide about the selection of research topics and methods and about the application of the results of scientific research. There will probably be disagreement and debate about the choice of values involved in these processes. A second conclusion from our short analysis is that in the second stage, epistemic values cannot be dismissed. Decisions about the acceptance of a hypothesis in favor of a rival one, or judgments which theory is preferable to guide ongoing scientific research, cannot be made without an appeal to epistemic values. Doing science without epistemic values is simply impossible -the strong value-free ideal is untenable and should be regarded as a false ideal.

In light of these reflections, question (C) about the effect of values on science can be confined to the possible impact of non-epistemic values on the acquisition of scientific knowledge (cf. Elliott 2011: 304). What effect does the involvement of, for instance, political ideologies and interests of commercial companies have on activities at the heart of science? This question leads to a number of problems. Suppose that non-epistemic values influence the process of acquiring scientific knowledge, do we then have to conclude that science is biased? Is the possible presence of non-epistemic values in this stage of science a hindrance to speak about objectivity, or do such values perhaps play a vital role in scientific practice, for example, in the construction of scientific theories? How can we prevent that the impact of non-epistemic values on science corrupts academic culture and harms the reliability and validity of scientific results (Radder 2010)? And if it is inevitable that non-epistemic values play a role in the acceptance of scientific knowledge, do we then need to construct an alternative conception of science, a "value-directed view of science," as Stenmark (2006) calls it?

This last question has been answered in the affirmative by Helen Longino and Heather Douglas, who offer analyses of science that acknowledge the role of non-epistemic values and include normative frameworks for diminishing their negative role while allowing for their positive role. Longino (1990: 76-81) submits that the solution of the problem can be found in the social character of science: scientific knowledge is always shared in a community of researchers. It is the communication and interaction between the members of a research community that can render scientific results objective and uncontaminated by prejudices and idiosyncrasies of individual scientists. Such objectivity is guaranteed if the scientific community allows for (1) recognized avenues for criticism (such as journals and conferences); (2) shared standards (the epistemic values 
mentioned above); (3) community response (criticism is taken seriously); and (4) equality of intellectual authority (of members of the community). Douglas (2009) approaches the problem in a different way. She distinguishes between direct and indirect roles for (non-epistemic) values, where values play a direct role when they "act as reasons in themselves to accept a claim, providing direct motivation for the adoption of a theory," while they play an indirect role when they "act to weigh the importance of uncertainty about the claim, helping to decide what should count as sufficient evidence for the claim" (Douglas 2009: 96). Douglas argues that non-epistemic values are allowable in scientific practice as long as they play an indirect role only.

In sum, the strong value-free ideal of science is untenable. Science cannot be practiced without epistemic values, and nobody will deny the role of non-epistemic values in the stages in which scientific research is selected and applied. The controversial issue is whether non-epistemic values are inevitable in processes of the evaluation and justification of scientific claims. If the influence of these values is indeed inevitable, then one can raise questions about (i) the impact of these values on the results of scientific research, (ii) the possibility to make them transparent, and (iii) the ways in which their impact may be diminished, if so desired. Since most science students are inclined to adopt the value-free ideal of science, it appears advisable to reflect on the role of values in science education. Why this is a good idea, and how this can be achieved, is the focus of the next sections.

\section{Introducing "Science and Values" in Undergraduate Education}

In the previous section, we have concluded that science is not value free. However, students often automatically start reasoning from a value-free point of view (Aalberts, Koster and Boschhuizen 2012; Koster and Boschhuizen 2018; Fisher and Moody 2002; King and Kitchener 2004). Usually students suppose that science is about the facts and only about the facts. They think that values play no role - or ought not to play a role - in the development of science. Here are some typical examples of statements by students about their own views before and after taking a reflective course (Koster and Boschhuizen 2018: 50):

- Before: "I was convinced that scientists are people who are completely objective."

- Before: "I regarded science simply as the truth."

- After: "Now I know that social and cultural factors influence what we regard as knowledge."

- After: "Now I know that full objectivity is unattainable. And that you are influenced, unconsciously, by your cultural, political or social background."

Since students are initially unaware of the interaction between science and values, they need to reflect upon (A) the difference between epistemic and non-epistemic values; (B) the role of these values in the selection, execution, and application of scientific research (stages 1, 2, and 3); and (C) the effects of values on science (the distinctions made in Section 2). In this section, we first substantiate our claim that undergraduate education should include reflection upon the role of values in science (3.1). Next, we demonstrate how students can be made aware of the interaction of science and (epistemic and non-epistemic) values in the first and the third stage (3.2) and in the second stage (3.3). Special attention is given to the consequences of the impact of values on science. 


\subsection{The Need for Education in "Science and Values"}

The recent philosophical insights about the role of values in science, sketched in Section 2, resulted from a naturalistic turn in philosophy of science that involved a shift from abstract, analytic accounts of science to approaches based on a study of scientific practice. The observation that in actual practice science is not and cannot be value free has led to the abandonment of the value-free conception of science. As Kelly and Licona (2018) argue, science education may profit from making a similar naturalistic turn, in which attention for actual epistemic practices takes center stage. We fully agree and accordingly we submit that science students should develop an awareness of, and an ability to reflect upon, possible interactions between science and values. To be sure, our proposal to include reflection on science and values in undergraduate science education is not completely novel, nor is it a very radical proposal: in the literature in science, education pleas for paying attention to values have been made before (e.g., Poole 1995; Corrigan et al., 2007; Corrigan and Smith 2015). However, we think that the insights that have emerged from the contemporary philosophical debates on science and values offer new resources for teaching undergraduate students and for developing concrete learning models that address the interaction between science and values.

There are at least three reasons why undergraduate students ought to reflect on the role of values in science: (i) to acquire an adequate and realistic conception of science, (ii) to prevent them from unconsciously adopting a false conception of science that may have misleading and dangerous consequences, and (iii) to prepare them for academic citizenship. We will discuss each of these reasons in turn.

First, students need to be informed about and critically reflect on the nature of science. Since they will practice, use, and/or evaluate scientific research themselves, it is important for them to think critically about the process of achieving scientific knowledge. They should acquire a realistic view of science, rather than the idealized picture that often dominates public debates. In particular, they should be aware of the influence of (hidden) assumptions on scientific methods, obtain realistic ideas about the reliability and limitations of scientific research, of the practice of scientific experiments, and of the nature of scientific laws and theories. To prevent misconceptions of science, it is also necessary for them to learn more about the interaction of science and values. ${ }^{9}$

Second, because students will very often become scientists, scientific practitioners, or academic professionals and since values will influence their future professional practices, it is important for them to reflect upon the role values may play in (i) the selection, (ii) the construction and evaluation, and (iii) the application of scientific knowledge. Since values can influence scientific practices, the presentation of science as entirely value free is deceptive and can have pernicious consequences. In the words of Kincaid et al. (2007: 4): "If scientific results concerning IQ and race, free markets and growth, or environmental emissions and planetary weather make value assumptions, treating them as entirely neutral is misleading at best." To prevent that value assumptions play a decisive role while hidden behind a cloak of neutrality, students need to become aware of the interaction of science and values at all levels (stages 1-3).

The view of science as being value free is also dangerous because it may hide the influence of certain values secretly supported by scientists themselves. Hans Radder (2010: 7-8), for instance,

\footnotetext{
${ }^{9}$ The focus on "knowledge production" in discussions on science and values could produce other misconceptions about science. Science is not just about knowledge production (cf. note 5). This need to be made clear in education on science as well.
} 
makes plausible that economic values are present in science by way of a variety of formal and informal personal ties. Individual scientists are increasingly running their own business, and some of them are holding externally sponsored professorships and chairs. Under the guise of neutrality, scientists can serve their own interests and - as is well documented in the case of pharmaceutical industries - sometimes even manipulate their evidence (Healy 1998, 2002). On the level of academic culture, it is sometimes claimed that science is structurally "colonized" by economic vocabularies and metaphors. With reference to colonization, Daniel Lee Kleinman speaks about "direct and indirect effects of industry on academic science" and sums up a number of mechanisms by which these effects are realized: the pressure to undertake research with obvious economic development potential, the shaping of efficacy standards by industry, and courses to teach scientists how to write a business plan or how to develop and implement financial plans (Kleinman 2010: 3139). The commodification of academic research is thus realized on individual and institutional levels. One of the strategies often mentioned to minimize the influence of economic values is the training and mentoring in research ethics (e.g., Resnik 2010: 86). An obvious prerequisite for such education is the critical reflection on the relation between science and values.

A third reason why students need to reflect on the interaction of science and values has to do with the ideal of "education for (academic) citizenship" (cf. Fuller 2000: 62-74). Academic citizenship is the ability of scientists, scientific practitioners, and academic professionals to reach beyond their own discipline and thus to reflect critically on the influence of, for instance, culture, belief, and commerce in their future professional practice. In today's pluralistic society, which features a multiplicity of approaches, points of view, values, and interests, this ability is of great importance. Education in science and values prepares students to acquire such a critical attitude inside and outside the academy.

\subsection{Values in the Selection and Application of Scientific Research}

Students need to think critically about the role of values in science. A first step to reach this goal is to make students aware that values are indeed involved in scientific research. There are at least two strategies to make students reflect upon the ideal of value-free science. A systematic strategy consists of a theoretical exposure about science and values (along the lines of the second section of this article). To be successful, this approach needs students who are able to understand sophisticated, philosophical arguments. If a course on science and values is developed for the benefit of students in philosophy, then this strategy will probably do. But if the course is meant for Bachelor students who did not receive any training in logic or other philosophical skills, then this is what they need to learn in the first place. For these students, another strategy is preferred: teaching by way of demonstration. By giving examples of the role of values in (renowned) scientific research, students become aware of the relevance and importance of the subject and of the problematic character of the value-free view of science. Ordering these examples (i) by distinguishing between the stages before actual research starts, in which research is conducted, and after it has finished, (ii) by making the distinction between epistemic and non-epistemic values, and (iii) by discussing the effects of values on science will stimulate students to reflect on the theme of science and values in a more structured and systematic way. Below we will indicate how this is done in an actual, second-year course for Bachelor students in one of the life sciences at the VU University of Amsterdam. In this course, entitled "Philosophy and Science," several examples are given to make students aware of the presence of values in science. These examples are also meant to stimulate critical reflection on the question 
whether or not these values play a legitimate role in science (Sections 3.2 and 3.3). Next, students are stimulated to reflect upon the values that influence their own scientific practices (Section 4).

An example of the interaction between science and values during the selection of research concerns the way in which a choice between biomedical approaches and clinical trials is made. Assuming that there is money available for only one type of research project, what are the reasons a funding organization can have for choosing between a proposal that focuses on the underlying mechanisms of a bodily disorder (biomedical approach) and a trial to determine the effect of a medicine to recover the patients suffering from the same disorder (clinical trial)? Students easily understand that values - epistemic values such as explanatory success, applicability, reliability, and scope on the one hand and social relevance and financial feasibility as examples of non-epistemic values on the other - are relevant for making a choice between these two research proposals. A more difficult, and more interesting, question is why certain values prevail over others.

The same holds for the influence of values on science in the application of scientific research. If medical research regarding a potentially dangerous influenza virus results in the development of an effective therapy, the answer to the questions of whether and, if so, how this therapy can be applied depends on the values involved. Epistemic values such as generality (the expected scope of the therapy) and non-epistemic values like safety (the degree of the health risks), individual freedom (should the therapy be prescribed compulsory?), and financial conditions determine the answer to these questions. It is clear that these answers, among others, depend on the political views (and ideological sources) of the government.

Students may be very apt to discuss these questions, and these discussions could indeed be helpful to better understand the interaction of science and values. However, for the aim of the course "Philosophy and Science," it is even more important and interesting to reflect on the influence of values in the second stage of scientific practices.

\subsection{Values at the Heart of Scientific Research}

In Section 2, we have seen that (i) epistemic values interact with processes of construction and evaluation of scientific knowledge and (ii) the most challenging question is whether nonepistemic values are legitimately involved in these processes. Here we present two examples that are discussed in the course "Philosophy of Science." These examples show, first, that epistemic values play an indispensable role in science and, second, that non-epistemic values are plausibly also part of scientific practice, at least in the examples discussed.

A classic analysis of the interaction of science and epistemic values is provided by Thomas Kuhn. Kuhn stressed the fact that "every individual choice between competing theories depends on a mixture of objective and subjective factors, or of shared and individual criteria" (Kuhn 1977: 325). The objective criteria include accuracy, consistency, scope, simplicity, and fruitfulness. These criteria play a vital role when a scientist has to choose between competing theories. However, as Kuhn showed by discussing some examples from the history of science, these criteria do not determine theory choice. He lists two sorts of difficulties: "individually the criteria are imprecise," and "when deployed together, they repeatedly prove to conflict with one another" (1977: 322). For both cases Kuhn presents convincing instances. Regarding the first difficulty, Kuhn shows that the 
criterion of "accuracy" cannot always discriminate between competing theories. One of his examples is the choice between heliocentric and geocentric systems: Copernicus' system was not more accurate than that of Ptolemy (until drastically revised by Kepler). Adding criteria such as consistency and simplicity does not eliminate the problem: both astronomical theories were internally consistent but inconsistent with certain existing scientific explanations, and the criterion of simplicity could as well be interpreted in favor of Ptolemy as in favor of Copernicus (Kuhn 1977: 322-325). Kuhn concludes that a choice between these theories cannot be made on the basis of the five objective criteria only. This is why he writes that these "objective criteria do not function as unambiguous rules, which determine choice, but as values, which influence it" (1977: 331). The criteria of choice must thus be supplemented by "subjective considerations" which are not the same as "bias and personal likes or dislikes" (Kuhn 1977: 337). Regarding the example of the two competing astronomical theories, the choice is regulated by scholarly backgrounds, individual experiences as a scientist, and values (Kuhn 1977: 325). Because the evidence plus a fixed set of epistemic values do not determine which theory must be preferred, the choice between competing scientific theories must be based on supplementary (and possibly nonepistemic) values.

Since a huge number of post-Kuhnian studies show in detail how values interact with science, many examples regarding the influence of values on the construction and evaluation of scientific claims could be given. Here we confine ourselves to the influence of values on the formulation of hypotheses regarding human evolution. In the 1950s and 1960s, Sherwood Washburn developed his theory of human evolution, centered on the concept of "man-the-hunter." According to Washburn and others, man evolved into a bipedal toolmaker with relatively large brains due to the organized hunting by males working as a team, which was seen as the crucial cause. "The biology, psychology, and customs that separate us from the apes - all these we owe to the hunters of the past" (Washburn and Lancaster 1975: 303). This theory suggests that the activity of men drove evolution forward, while women, gathering food and giving birth, were not important for the coming into existence of Homo sapiens (Haraway 1989: 186-230). During the 1970s, two alternative theories, assigning a major role to the changing behavior of females, were developed. The first one - proposed by Sally Slocum and later further developed by Nancy Tanner and Adrienne Zihlman - was called the "woman-the-gatherer hypothesis." This theory states that the major cause for the high level of the development of tools was the need of women to gather scarce vegetable food (Haraway 1989: 127, $228 \mathrm{f}$., 331-348). The second was famously formulated by Sarah Hrdy. Her story of the origin of (wo)mankind makes use of sociobiological theories applying evolutionary theory to the development of behavior. The key word in her theory is "strategy." Female apes invest in reproductive strategies that enlarge the probability of survival of their offspring: by mating with dominant and aggressive males, they diminish the chance that other males will kill their descendants. According to Hrdy, these kinds of evolutionary strategies are crucial factors in the explanation of the origin of modern man: "the central organizing principle of primate social life is competition between females and especially female lineages" (Haraway 1989: 349; cf. 349-367). The differences between these theories, especially between the ones proposed by Washburn and Hrdy, can partly be explained by the different field studies of primates and by the emergence of sociobiology. However, since the available evidence underdetermines their theories, it is highly plausible that the different perspectives on the role of men and women in society function as hidden background 
assumptions. From the point of view of Washburn, it was self-evident that human beings were men and that public life was centered on their activities. From the feminist perspective of Hrdy, much lost ground had to be made up by women. This example shows that the formulation of scientific theories is unconsciously (and perhaps sometimes consciously) influenced by non-epistemic values (Theunissen 2004: 129-146; cf. Longino 1990: 103132).

The presentation of these examples is carried out during the lectures. In meetings of the group tutorials (approximately 20 students), there is room to evaluate these examples, to critically discuss them, and to ask more fundamental questions about, for instance, the (il)legitimate role of non-epistemic values in science and whether the presence of these values in science automatically entails that science is biased. This is done via a number of assignments.

One of the assignments is explicitly meant to discuss Longino's view on science as a social enterprise. The assignment is constructed around two examples of recent research in the life sciences and is related to the absence or presence of (i) a diversity of scientific approaches and (ii) proper functioning feedback mechanisms. The first example is about the competition between adherents of the "out-of-Africa-thesis" and the "multiregional hypothesis." On the basis of archeological data (the fossil record), it could not be decided which of the two models was preferable. Until the late $1980 \mathrm{~s}$, the two theories were underdetermined by the available evidence. A choice between the two models had to be based on non-epistemic values - a conclusion the students have to find out by themselves. New evidence suggested (among others from the fields of genetics and linguistics) that the "out-of-Africa-thesis" was the most reliable (Lewin and Foley 2004: 331-421). In this case, new evidence coming from other scientific fields allowed for a choice between the two competing models. The students have to argue whether this choice was indeed solely based on epistemic values. This is not indisputable, because "evidence" can be influenced by, for instance, ideologies and interests and is sometimes even consciously manipulated (cf. Radder 2010).

The second example in the assignment - concerning research on the effectiveness of medicines - illustrates how a diversity of scientific approaches is valuable for the practice of science. Because the development and testing of medicines are very expensive, usually only one type of organization is involved in this process: the pharmaceutical industry. The monopoly of these companies in combination with their financial interests undermines the effectiveness of feedback mechanisms such as double-blind experiments, peer review, and statistical tests (Radder 2010). Accordingly, drug research could benefit from a diversity of scientific perspectives and from independent institutional controls and testing methods: the current risk of bias and manipulation due to the pharmaceutical industry's monopoly could then be diminished or even eliminated. Students reflect on this claim with help of Longino's thoughts on the way objectivity can be guaranteed by the scientific community. They try to find out what the effect on medical research would be if the four conditions mentioned by Longino would be fulfilled in this example.

\subsection{Values: From Awareness to Self-Awareness}

The examples given in Sections 3.2 and 3.3 all support the conclusion that science is value laden or, to put it more carefully, that the value-free view of science is far from self-evident. By presenting these kinds of examples, students become acquainted with the possibility that values play a role in scientific research. They learn that epistemic and non-epistemic values 
influence the processes of acquiring, formulating, and accepting scientific knowledge. Through the structured presentation of these case studies, students are challenged to think in a more systematic way about the interaction of science and values. Questions about the objectivity of science are also raised.

The course shows the complex relation between science and values in the scientific discipline of the students, but usually none of this is seen by them to apply directly to the role of values and convictions regarding their own scientific practices. Due to the way textbooks teach them to think about science, they still think of themselves as value-free agents of science (Aalberts, Koster and Boschhuizen 2012). During their studies, however, students become themselves more and more involved in the process of scientific research, and this process is thus (possibly unnoticed) influenced by epistemic and perhaps even non-epistemic values. Hence, the question arises in which way teachers can stimulate students to reflect upon the impact of values on their own scientific activities.

While students may learn a lot about the interaction between science and values via studying philosophical literature, examples, and case studies, this may not immediately lead to awareness of and reflection on how their own scientific practice is value-laden. This was already noticed by John Dewey. According to Dewey, one's mental attitude is not necessarily changed by the teaching of science as subject matter and by engaging in, for instance, physical manipulations in a laboratory (Dewey 1910/1995: 125). For Dewey, experience is the key to science education: experiences have the power to transform our concepts and deep-seated convictions about science (Dewey 1938/1997). Based on this idea, he defines education "as a continuing reconstruction of experience" (Dewey 1897/2008: 107). Dewey argues that conducting scientific inquiry can provide students with the ability to make informed decisions through value judgments. It would be a challenge to connect scientific inquiry and values in science education by starting from Dewey's approach (cf. Lee and Brown 2018), given recent criticisms on aspects of his work (e.g., Radder 2019: 256-260; Roothaan 2014: 220-221). In this paper, however, we will not pursue this idea but propose a different approach to relate scientific inquiry to values in science education. In the next section, we use this approach to develop a concrete learning model.

\section{The Dilemma-Oriented Learning Model (DOLM)}

Reflection on values in scientific research will be an important step in the development of a critical approach to science. By scrutinizing different case studies in the life sciences, students begin to understand that the value-free view of science is problematic and possibly false. Values matter in science. Because students will become scientists, scientific practitioners, or academic professionals themselves, they need to think critically about the way their own values interact with science. Because these values are so deeply embedded in their way of doing and thinking, it is a difficult task to, first, identify and, next, discuss them. It is relatively easy to see how values that are not our own are part of the research process in an implicit and unacknowledged way. But it is much harder to recognize that our own ways of observing and conceiving the world contain values which could be just as prominent. Reflection upon one's own values is thus necessary.

Understanding the way scientific knowledge is acquired and reflecting upon the students' own values are the goals of the Bachelor course "Philosophy and Science" for students of Biomedical Sciences at the Vrije Universiteit Amsterdam. In the first part of this course, 
students become acquainted with the role of epistemic and non-epistemic values in science (as discussed in the previous section), while during the second part, the emphasis is on the interaction of science and one's own values. In this section, we will describe the second part of this course and explain how the "Dilemma-Oriented Learning Model" (DOLM) can help to reflect upon one's own values. In Sections 4.1 and 4.2, we explain DOLM, and in Section 4.3, we show how DOLM is used in the course "Philosophy and Science."

\subsection{High-Potential Issues as Pedagogical Tools}

DOLM can be applied to cases of complex issues in which scientific knowledge is involved so-called "high-potential issues". High-potential issues have two features: they cannot be defined with a high degree of completeness, and they cannot be solved with a high degree of certainty. As pedagogical tools, such issues have the potential (i) to teach students how to evaluate facts and theories, (ii) to make them aware of underlying (sources of) values, and (iii) to clarify, structure, and weigh their arguments regarding their choice in the dilemma so they can take positions and make choices based on considered judgments (Boschhuizen, Aalberts, and Koster 2007). This is why high-potential issues are helpful for reflecting on the relation between science and values.

An example of a high-potential issue is the choice between conventional medicine and homeopathy. In a systematic evaluation based on the evidence-based method by Aijing Shang and colleagues in The Lancet (Editorial 2005), the conclusion was drawn that homeopathy is out of date and defeated. The editorial address summarized the article with the following telling statement: "The end of homeopathy." Shang et al. write that homeopathy fares poorly when compared with conventional medicine. Although many people use homeopathic remedies, the reported positive results seem to be consequences of the placebo effect. Shang et al. $(2005,726)$ suggest that positive findings of trials of homeopathy can be explained by referring to bias.

However, this did not entail the end of homeopathy. In the Netherlands, representatives of the Dutch Royal Association for Homeopathy rejected the conclusions of The Lancet (Koster 2014). One of their main criticisms concerned the use of the evidence-based method. They claimed that this method cannot be applied in the case of homeopathy. Homeopathic remedies are fine-tuned: they are developed for individual patients, and the same remedy cannot be given to a random group of individuals. Instead of evidence-based medicine, they argue in favor of observational methods such as cohort studies. Therefore, the approach of Shang et al. can also be accused of bias, in this case regarding the method (Boschhuizen, Aalberts, and Koster 2008).

This discussion suggests that such questions, and other complex issues in the life sciences, cannot be answered simply by referring to "the facts." Reflection on methodology and evaluation of, for instance, claims about possible biases are also necessary. Next to this, underlying assumptions related to (sources of) epistemic and non-epistemic values play an important but usually hidden role in the assessment of the claims under discussion. The former values may concern the nature of reality, the essential characteristics of explanatory mechanisms, and the question of what can be considered as evidence, while the latter may relate to, for example, the reputation of journals, financial interests of scientists and pharmaceutical industries, and ideological views on science. What is needed is a judgment in which implicit values are made explicit and in which the arguments are considered and evaluated. This is why 
the debate about conventional medicine and homeopathy can be seen as an example of a "high-potential issue."

Confronting students with this kind of issues makes them aware of the complexity of the evaluation of scientific research and helps them to acquire critical abilities in general and to develop "broad-mindedness" and "responsibility" in particular. Broad-mindedness can be characterized by receptiveness to new and different ideas or the opinions of others. Developing broad-mindedness is a process that is sometimes called "transformative learning" (Mezirow et al., 1990, xvi), because it results in the reformulation of one's frame of reference - in which underlying values are central - to allow a more inclusive, discriminating, and integrative understanding of one's experience. In the context of the choice between conventional medicine and homeopathy, the aim is to critically evaluate and broaden students' views on, for instance, evidence-based practices. Responsibility is seen here as students' willingness and ability to account for their choices and actions and to make clear how they relate to their own (underlying) values. The development of students' critical abilities such as broadmindedness and responsibility corresponds with the learning goals of the course under scrutiny.

The use of high-potential issues in education can be compared to the application of socioscientific issues as pedagogical tools. It is argued, for instance, that such tools are helpful to develop argumentation skills in students (Christenson et al. 2014) and to make them aware of the role of knowledge, values, and experiences in their argumentation (Rundgren et al. 2016). While some studies are thus positive about the use of these tools, others are more critical. Lee (2007), for instance, found that students need a lot of guidance to develop the ability to make informed decisions on socio-scientific issues (176): "The results of the trials show that teachers need to take students through a critical examination of scientific evidence and engage them in logical argumentation to put their views in perspective and avoid bias." Tal and Kedmi (2006) argue that the use of socio-scientific issues in education enlarges students' argumentation skills but that traditional content-based textbooks written from a value-free perspective keep students away from a critical thinking culture. Furthermore, it has been shown that students use nonepistemic values (such as personal, social, and cultural values) in thinking about socioscientific issues, without relying on inquiry-based learning or by selectively using scientific evidence (Lee and Brown 2018: 66-68).

In the next section, we introduce another pedagogical tool: DOLM. DOLM has been developed to help students reflect upon, to broaden, and to give an account of one's underlying (sources of) values or, in Mezirow's terminology, one's frame of reference (Boschhuizen, Poortinga and Aalberts 2006, Koster, Aalberts and Boschhuizen 2009; Mezirow et al. 1990). The tool of DOLM allows students to become aware of the role that (non-epistemic) values play in their decision-making, and it teaches them to explicitly reflect on the way they use scientific knowledge.

\subsection{Introduction of DOLM}

DOLM is a four-phase model, which starts with a case study involving a high-potential issue a "dilemma" in terms of DOLM. Students make distinct choices by reflecting on the significance of their choices: reflection on intuitive ideas (Phase A), reflection on the relevant scientific knowledge (Phase B), and philosophical reflection (Phase C). Reflection on (sources of) values cuts across phases A, B, and C. In a more retrospective assignment (phase D), students look back on their choices and arguments (see Fig. 1). This is meant to raise their 


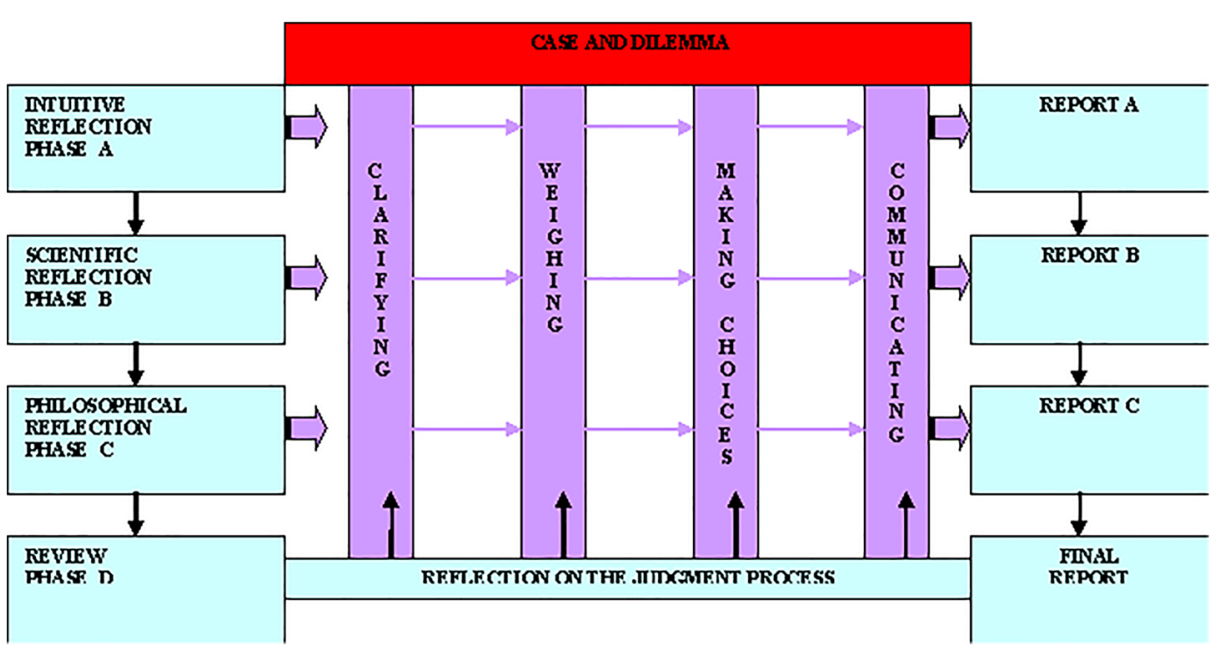

Fig. 1 Diagram of the Dilemma-Oriented Learning Model

awareness of how they gauge the value and evaluate knowledge, how their values influence this process, and how they appreciate and apply the different kinds of reflection as an act of critical self-reflections.

During each of the phases A, B, and C, students take three steps: (1) they clarify their commitment to certain theories, methods, and (sources of) values; (2) they weigh the importance and significance of these theories, methods, and (sources of) values; and (3) they make a reasoned choice. A special point of interest is the use of dialogue as a means of communication about students' choices and arguments. Students are encouraged to reflect together with their peers and tutor. This dialogue confronts them with their own values and with the values of other students. In addition, it teaches them to take seriously each other's underlying sources of epistemic and non-epistemic values and to enter into an open-minded discussion about each other's views. After each phase, students record their experiences in a report. The report after phase D gives a summary of the learning process (Aalberts, Koster and Boschhuizen 2012).

\subsection{DOLM in the Life Sciences}

DOLM has been integrated into the course "Philosophy and Science." In this course, students study texts, attend lectures and classes, hand in "reflection tasks," read and comment each other's assignments, and discuss topics like the relation between science and values, the role of epistemic and non-epistemic values in the formulation and acceptance of scientific knowledge, and the influence of their own point of view on the practice of science. In the course, the dilemma between conventional medicine and homeopathy is used to reflect on the question: "What is science?". Students are given an assignment in which they are asked to take on the role of a policy advisor at the "Foundation for Drug Development," responsible for financing scientific research into new medicines, to the amount of EUR 500,000. Two requests have been submitted. The first concerns clinical research for a new, conventional cancer medicine specially developed to eliminate side effects. The second concerns a cohort study for a new homeopathic treatment to eliminate the side effects of cancer medicines. Only one of the requests can be granted. Which one is the question for the policy advisor. 
In Phase A, students opt for one of the two clinical studies based on their own experiences and values, intuitive ideas about conventional medicine and homeopathic remedies, and relevant scientific knowledge achieved in other courses. In this phase, students defend their choices quite straightforwardly, sometimes without further arguments: "We have chosen for conventional medicine based on our own experiences. Our education has strengthened our choice" (Boschhuizen, Aalberts, and Koster 2008). In the next step (Phase B), they critically think about the claims of evidence-based medicine and the characteristics of homeopathic remedies, and they learn to consider the dilemma from distinct perspectives. This can result in a more balanced view: "I've taken the side of homeopathy two times now, and am developing some understanding for its opponents. Their arguments, however, were not convincing" (Koster, Aalberts and Boschhuizen 2009). In particular, they are confronted with points of view in which homeopathy is severely criticized because of its implausible principles and its lack of explanatory power, and with positions that are in favor of homeopathy because of positive experiences and of research concluding that homeopathic medicines do have significant effects. They are also introduced to efforts that try to explain these significant effects. This new information sometimes results in a different point of view: "I have altered my position because, after careful consideration of my original viewpoint, I was ultimately convinced by the opposing points of view" (Koster, Aalberts and Boschhuizen 2009). Because of the introduction of these different points of view, students again realize that (sources of) values influence scientific research. In this phase, the students begin to attach importance to the question whether homeopathic medicine can be considered a scientific approach or not. To answer this question, philosophical reflection upon the question "What is science?" is needed (Phase C). In this part of the course, students examine and critically reflect upon different perspectives on science such as the empirical cycle of the logical positivists, Karl Popper's idea of falsification, Thomas Kuhn's concept of scientific paradigms, Harry Collins' reading of the sociology of scientific knowledge, and some positions in social epistemology. This can result in a more reflective perspective on their choice between conventional medicine and homeopathy: “.... and our own paradigm has also played a role in our decision-making. By executing tasks, we realized this point more and more... However, if we had had a completely different paradigm, we would probably have made another choice" (Boschhuizen, Aalberts, and Koster 2007). Central to the lectures about these different perspectives is the way they conceptualize, evaluate, or simply discard the relation between science and values.

One of the aims of the course is that students learn to think about (the sources of) their values, (if necessary) reformulate their perspectives on science, and make choices concerning the dilemma based on considered judgments. For that constructive process, dialogue is an essential ingredient. Of course, the aim will sometimes also be reached during the lectures or when students study the texts related to subjects from Phase B and C. It is quite natural that some students will then reframe their system of underlying values. But, as Paul Feyerabend $(1975,31)$ wrote, "prejudices are found by contrast, not by analysis." Applying this thought to the context of the course, it follows that a direct analysis of the role of our own values in our perspective on science normally will not work. By analyzing them, they will hardly become apparent. We need the confrontations with other views, with opposing stances, to become aware of (the sources of) our own values and presuppositions (cf. Pera 1994; Weigand and Dascal, 2001). In short, we need dialogue.

How can this dialogue be stimulated? During the group tutorials, students present their positions regarding the dilemma. These positions are typically not only different in the choice for or against conventional medicine or homeopathy, the grounds that one student puts forward 
may also differ from the grounds of another student. By confronting each other with these various claims, grounds, and reasons and by discussing them - with respect for each other's stances - it is possible to become aware of the values involved in the argument. The dialogue makes it possible to reflect explicitly on the various aspects of the student's judgment: relevant scientific knowledge, the social aspects of the issue, the normative-ethical aspects of possible choices, one's own values, world view and (non)religious beliefs, and the interrelations between all these. In this way, students have the possibility to become aware of their own and each other's (sources of) values and to think critically about them. This aim of the course is not easily reached: first, students need a lot of practice in recognizing underlying values and in using their imagination to redefine issues from different perspectives. Second, teachers need to learn how they can facilitate the analysis of (sources of) values and dialogue. To facilitate the dialogue, it is important that a safe environment is created in which students act respectfully, are open-minded, and show interest in each other's views and in which everyone accepts the agreements about the dialogical method in the classroom. As mentioned, it is not easy to create these conditions and to achieve the aim of the course. But if it is successful, then one of the main goals of the course - awareness of the relation between science and values - is reached. Elsewhere one of us and two colleagues from VU University Amsterdam have shown that this approach is actually quite successful (Aalberts, Koster and Boschhuizen 2012). ${ }^{10}$

In the retrospective assignment (phase D), students look back on their choices and arguments. In particular, they reflect on the way epistemic and non-epistemic values influenced their choice and in which way they now think about the possible involvement of non-epistemic values: could this involvement have been avoided or eliminated? Or did they find ways to handle these values in the way suggested by, for instance, Longino?

\section{Conclusion}

In this article, we have shown that the strong value-free ideal of science is untenable. Epistemic and non-epistemic values are present in scientific practices, in particular in the stages in which scientific research is selected and applied. We have seen that epistemic values play an indispensable role in what might be called "the heart of science": they necessarily influence the evidential standards needed for justifying a claim. Whether non-epistemic values are inevitably involved in the assessment of scientific claims is a more controversial issue. However, when these values are involved in processes of evaluation and justification, the question is whether this implies that science is hopelessly biased. Some philosophers of science defend that even if this is the case, it is still possible to retain the objectivity of science.

We have argued that students need to be aware of these interactions between science and values. Therefore, it is necessary to pay attention to this subject during undergraduate education. This is best done by way of presenting instances of value-laden research. In this way, students become acquainted with the influence of epistemic and non-epistemic values on the formulation and acceptation of scientific knowledge. They thus learn that the value-free view of science is inadequate. Furthermore, they are stimulated to critically think about the possible effects of the involvement of values on science. The next step consists in reflecting upon students' own frame of reference: in which way do values influence their own approach

\footnotetext{
${ }^{10}$ A description and analyses of empirical research to the effects of DOLM courses, learning outcomes, and measures for improving courses can be found in Aalberts, Koster and Boschhuizen (2012: 446-453).
} 
of science? By way of high-potential issues, incorporated in DOLM, students are stimulated to rethink the influence of their own values on scientific practices. We thus aim for what may be called "Effective Reflective Education" (Koster and Boschhuizen 2018).

According to Helen Longino, the objectivity of science can be guaranteed by the social character of science - as long as the scientific community fulfils the four conditions of a genuine dialogue (cf. Section 2). In other words, critical discussion among scientists who work from different perspectives, assumptions, or worldviews and/or use different methodologies and approaches will enhance the reliability of the resulting scientific claims. We have seen that dialogue is also important as a means to reflect on one's own values in science education. Students need the confrontation with other views to become aware of their own (sources of) values. Accordingly, we conclude that diversity may be productive not only for the development of science but also for the reflection on scientific practices in undergraduate education.

Acknowledgments We would like to thank two anonymous reviewers for helpful suggestions; Rob Boschhuizen and Hans Radder for their support and advice; and the members of the research group Philosophy of Science and Technology, Vrije Universiteit Amsterdam, for fruitful discussion of earlier versions of this work. This publication was made possible through the support of a grant from the Varieties of Understanding Project at Fordham University and the John Templeton Foundation. The opinions expressed in this publication are those of the authors and do not necessarily reflect the views of TempletonWorld Charity Foundation.

\section{Compliance with Ethical Standards}

Conflict of Interest The authors declare that they have no conflict of interest.

Open Access This article is distributed under the terms of the Creative Commons Attribution 4.0 International License (http://creativecommons.org/licenses/by/4.0/), which permits unrestricted use, distribution, and reproduction in any medium, provided you give appropriate credit to the original author(s) and the source, provide a link to the Creative Commons license, and indicate if changes were made.

\section{References}

Aalberts, J., Koster, E., \& Boschhuizen, R. (2012). From prejudice to reasonable judgement: integrating (moral) value discussions in university courses, Journal of Moral Education, 41, 437-455.

Allchin, D. (1999). Values in science: an educational perspective. Science \& Education, 8, 1-12.

Boschhuizen, R., Poortinga, J. \& Aalberts, J. (2006). Reflective judgment learning at the Vrije Universiteit Amsterdam. Dilemma driven learning. A teacher guide. Amsterdam: Centre for Educational Training, Assessment and Research (CETAR), VU University.

Boschhuizen, R., Aalberts, J.M.C., \& Koster, E. (2007). Preparing Dutch undergraduates for lives of moral and civic responsibility. Paper presented at the 33rd Annual Conference of the Association for Moral Education. New York, NY, USA, November 15-17.

Boschhuizen, R., Aalberts, J.M.C., \& Koster, E. (2008). Challenging students' 'broad-mindedness' at VU university Amsterdam. Paper presented at the 34th Annual Conference of the Association for Moral Education, University of Notre Dame, South Bend, IN, November 13-16.

Carrier, M. (2008). Introduction (pp. 1-13). Howard \& Kourany: Science and the social. In Carrier.

Carrier, M., Howard, D., \& Kourany, J. (Eds.). (2008). The challenge of the social and the pressure of practice: science and values revisited. Pittsburgh: University of Pittsburgh Press.

Christenson, N., Rundgren, S.-N. C., \& Zeidler, D. L. (2014). The relationship of discipline background to upper secondary students' argumentation on socioscientific issues. Research in Science Education, 44, 581-601.

Corrigan, D., Dillon, J., \& Gunstone, R. (Eds.). (2007). The re-emergence of values in science education. Rotterdam: Sense. 
Corrigan, D., \& Smith, K. (2015). The role of values in teaching and learning science. In J. Deppeler, T. Loreman, R. Smith, \& L. Florian (Eds.), Inclusive pedagogy across the curriculum (pp. 99-117). Emerald Publishing.

Dewey, J. (1897/2008). My pedagogic creed. Reprinted in T.W. Johnson and R.F. Reed (eds.). Philosophical documents in education. Boston: Pearson, 103-110. (First published in The School Journal LIV (3), 77-80 (January 16, 1897).)

Dewey, J. (1910). Science as subject-matter and method. Science, 31 (787), 121-127. (Reprinted in Science \& Education 4 (1995) pp. 391-398).

Dewey, J. (1938/1997). Experience and education. New York: Touchstone.

Dorato, M. (2004). Epistemic and nonepistemic values in science, in: Machamer \& Wolters (2004), 52-77.

Douglas, H. (2009). Science, policy, and the value-free ideal. Pittsburgh: University of Pittsburgh Press.

Douglas, H. (2016). Values in science. In P. Humphreys (Ed.), The Oxford handbook of philosophy of science (pp. 609-630). New York: Oxford University Press.

Dupré, J. (2007). Fact and value. In H. Kincaid, J. Dupré, \& A. Wylie (Eds.), Value-free science: ideal or illusion? (pp. 27-41). New York: Oxford University Press.

Editorial (2005). The Lancet 366, 690.

Elliott, K. C. (2011). Direct and indirect roles for values in science. Philosophy of Science, 78, 303-324.

Elliott, K. C. (2017). A tapestry of values: an introduction to values in science. New York: Oxford University Press.

Feyerabend, P. K. (1975). Against method. London: Verso.

Fisher, K. M., \& Moody, D. E. (2002). Student misconceptions. In K. M. Fisher, J. H. Wandersee, \& D. E. Moody (Eds.), Mapping biology knowledge (pp. 55-57). New York: Kluwer.

Fuller, S. (2000). The governance of science: ideology and the future of the open society. Buckingham: Open University Press.

Haraway, D. (1989). Primate visions: gender, race, and nature in the world of modern science. London: Routledge.

Healy, D. (1998). The Antidepressant Era. Cambridge: Harvard University Press.

Healy, D. (2002). The Creation of psychopharmacology. Cambridge, MA: Harvard University Press.

Intemann, K. (2005). Feminism, underdetermination, and values in science. Philosophy of Science, 72, 10011012.

Kelly, G. J., \& Licona, P. (2018). Epistemic practices and science education. In M. Matthews (Ed.), History, Philosophy and Science Teaching (pp. 139-166). Dordrecht: Springer. https://doi.org/10.1007/978-3-31962616-1 5.

Kincaid, H., Dupré, J., \& Wylie, A. (2007). Introduction. In H. Kincaid, J. Dupré, \& A. Wylie (Eds.), Value-Free Science? Ideals and Illusions (pp. 3-23). Oxford: Oxford University Press.

King, P. M., \& Kitchener, K. S. (2004). Reflective judgment: theory and research on the development of epistemic assumptions through adulthood. Educational Psychologist, 39, 5-18.

Kleinman, D. L. (2010). The commercialization of academic culture and the future of the university. In H. Radder (Ed.), The Commodification of Academic Research. Science and the Modern University (pp. 24-43). Pittsburgh: University of Pittsburgh Press.

Koster, E. (2014). Reguliere en alternatieve geneeskunde. In E. Koster (Ed.), Wat is wetenschap? Een filosofische inleiding voor levenswetenschappers en medici (pp.85-102). Amsterdam: VU University Press.

Koster, E., \& Boschhuizen, R. (2018). Glazen slijpen. Onderliggende denkramen in academisch onderwijs. Eindhoven: Damon.

Koster, E., Aalberts, J.M.C., \& Boschhuizen, R. (2009). Philosophy as a turning-point in academic judgement learning? Paper presented at the 4th Conference of the Asia Pacific Network for Moral Education, Seoul, Korea, May 22-24.

Kuhn, T. S. (1977). Objectivity, value judgment, and theory choice. In The Essential Tension. Selected Studies in Scientific Tradition and Change (pp. 320-339). Chicago: University of Chicago Press.

Lacey, H. (1999). Is Science value free? Values and scientific understanding. London: Routledge.

Laudan, L. (1984). Science and Values. The aims of science and their role in scientific debate. Berkeley: University of California Press.

Lee, Y. C. (2007). Developing decision-making skills for socio-scientific issues. Journal of Biological Education, $41,170-177$.

Lee, E. A., \& Brown, M. J. (2018). Connecting inquiry and values in science education: An approach based on John Dewey's philosophy. Science \& Education, 27, 63-79.

Lewin, R., \& Foley, R. A. (2004). Principles of human evolution. Oxford: Blackwell.

Longino, H. E. (1990). Science as social knowledge. Values and Objectivity in Scientific Inquiry. Princeton University Press: Princeton.

Longino, H. E. (1995). Gender, politics and the theoretical virtues. Synthese, 104, 383-397. 
Longino, H.E. (2004). How values can be good for science. In: Machamer \& Wolters (2004), 127-142.

Machamer, P., \& Wolters, G. (Eds.). (2004). Science, values, and objectivity. Pittsburgh: University of Pittsburgh Press.

McMullin, E. (1983). Values in science. In P. D. Asquith \& T. Nickles (Eds.), PSA 1982 Vol.2 (pp. 3-28). East Lansing: Philosophy of Science Association.

McMullin, E. (2000). Values in science. In W. H. Newton-Smith (Ed.), The Blackwell Companion to the Philosophy of Science (pp. 550-560). London: Blackwell.

Mezirow, J., et al. (1990). Fostering critical reflection in adulthood: A Guide to Transformative and Emancipatory Learning. San Francisco: Jossey-Bass.

Pera, M. (1994). The discourses of science. Chicago, IL: The University of Chicago Press.

Poole, M. (1995). Beliefs and values in science education. Buckingham: Open University Press.

Pournari, M. (2008). The distinction between epistemic and non-epistemic values in the natural sciences. Science \& Education, 17, 669-676.

Radder, H. (Ed.). (2010). The commodification of academic research. Science and the Modern University. Pittsburgh: University of Pittsburgh Press.

Radder, H. (2019). From commodification to the common good: reconstructing science, technology, and society. Pittsburgh: University of Pittsburg Press.

Resnik, D.B. (2010). Financial interests and the norms of academic science. In H. Radder (Ed.), The Commodification of Academic Research. Science and the Modern University (pp.65-89). Pittsburgh: University of Pittsburgh Press.

Rooney, P. (1992). On values in science: Is the epistemic/non-epistemic distinction useful? In D. Hull, M. Forbes, \& K. Okruhlik (Eds.), PSA 1992: Proceedings of the Biennial Meeting of the Philosophy of Science Association, Vol.2 (pp. 13-22). East Lansing.

Roothaan, A. (2014). Decommodification of learning: John Dewey and Ivan Illich in search of an education for the future. In H. W. de Regt \& C. L. Kwa (Eds.), Building bridges: connecting science, technology and philosophy (pp. 217-228). Amsterdam: VU University Press.

Rundgren, C. J., Eriksson, M., \& Rundgren, S.-N. C. (2016). Investigating the intertwinement of knowledge, value and experience of upper secondary students' argumentation concerning socioscientific issues. Science \& Education, 25, 1049-1071.

Shang, A., et al. (2005). Are the clinical effects of homoeopathy placebo effects? Comparative study of placebocontrolled trials of homoeopathy and allopathy. The Lancet, 366, 726-732.

Stenmark, M. (2006). Rationality and different conceptions of science. In F. LeRon Shults (Ed.), The Evolution of Rationality (pp. 47-72). Eerdmans: Michigan.

Tal, T., \& Kedmi, Y. (2006). Teaching socioscientific issues: classroom culture and students' performances. Cultural Studies of Science Education, 1, 615-644.

Theunissen, B. (2004). Diesels droom en Donders' bril. Hoe wetenschap werkt. Nieuwezijds.

Washburn S.L \& Lancaster, C.S. (1975). The evolution of hunting. In: R.B. Lee and I. Devore (ed.), Man the Hunter, Chicago: Aldine Publishing Company, 293-303.

Weigand, E., \& Dascal, M. (Eds.). (2001). Negotiation and power in dialectic interaction. Amsterdam: John Benjamins Publishing Company.

Publisher's Note Springer Nature remains neutral with regard to jurisdictional claims in published maps and institutional affiliations. 